\title{
Increased endothelial activation in recently symptomatic versus asymptomatic carotid artery stenosis and in cerebral microembolic-signal-negative patient subgroups
}

\author{
J. A. Kinsella ${ }^{a}$, W. O. Tobin ${ }^{a}$, G. F. Kavanagh ${ }^{a}$, J. S. O'Donnell ${ }^{b}$, R. T. McGrath ${ }^{b}$, S. Tierney ${ }^{c}$,

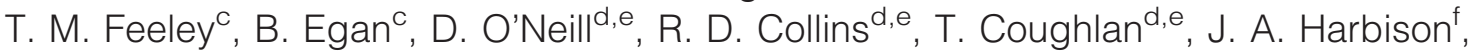 \\ C. P. Doherty ${ }^{\text {, }}$ P. Madhavan ${ }^{h}$, D. J. Moore ${ }^{h}$, S. M. O'Neill ${ }^{h}$, M.-P. Colgan ${ }^{h}$, M. Saqqur', \\ R. P. Murphy ${ }^{a, e}$, N. Moran', G. Hamilton ${ }^{k}$ and D. J. H. McCabe ${ }^{a, e, l}$ \\ a Department of Neurology, Adelaide and Meath Hospital, Dublin, incorporating the National Children's Hospital, Trinity College Dublin, \\ Dublin; ${ }^{\mathrm{b}}$ Haemostasis Research Group, St James's Hospital, Trinity College Dublin, Dublin; ${ }^{\mathrm{c}}$ Department of Vascular Surgery, Adelaide and \\ Meath Hospital, Dublin, incorporating the National Children's Hospital, Trinity College Dublin, Dublin; ${ }^{\mathrm{d}}$ Department of Age-Related Health \\ Care, Adelaide and Meath Hospital, Dublin, incorporating the National Children's Hospital, Trinity College Dublin, Dublin; ${ }^{\mathrm{e}}$ Stroke Service, \\ Adelaide and Meath Hospital, Dublin, incorporating the National Children's Hospital, Trinity College Dublin, Dublin; ${ }^{\mathrm{f}}$ Department of Medi- \\ cine for the Elderly/Stroke Service, St James's Hospital, Trinity College Dublin, Dublin; ' Department of Neurology, St James's Hospital, \\ Trinity College Dublin, Dublin; ${ }^{\mathrm{h}}$ Department of Vascular Surgery, St James's Hospital, Trinity College Dublin, Dublin, Ireland; ${ }^{\mathrm{i}}$ Division of \\ Neurology, Department of Medicine, Walter C Mckenzie Center, University of Alberta, Edmonton, AB, Canada, ${ }^{\mathrm{j} D e p a r t m e n t ~ o f ~ M o l e c u l a r ~}$ \\ and Cellular Therapeutics, Royal College of Surgeons in Ireland, Dublin, Ireland; ${ }^{\mathrm{k}}$ University Department of Surgery, Royal Free Hampstead \\ NHS Trust, London; and ${ }^{1}$ Department of Clinical Neurosciences, Royal Free Campus, UCL Institute of Neurology, London, UK
}

\section{Keywords:}

carotid stenosis, cerebral microemboli, stroke, transient ischaemic attack, von Willebrand factor

Received 27 November 2013 Accepted 7 February 2014
Background and purpose: von Willebrand factor propeptide (VWF:Ag II) is potentially a more sensitive marker of acute endothelial activation than von Willebrand factor antigen (VWF:Ag). These biomarkers have not been simultaneously assessed in asymptomatic versus symptomatic carotid stenosis patients. The relationship between endothelial activation and cerebral microembolic signals (MESs) detected on transcranial Doppler ultrasound is unknown.

Methods: In this multicentre observational analytical study, plasma VWF:Ag and VWF:Ag II levels in patients with $\geq 50 \%$ asymptomatic carotid stenosis were compared with those from patients with $\geq 50 \%$ symptomatic carotid stenosis in the 'early' ( $\leq 4$ weeks) and 'late' ( $\geq 3$ months) phases after transient ischaemic attack or ischaemic stroke. Endothelial activation was also longitudinally assessed in symptomatic patients during follow-up. Transcranial Doppler ultrasound monitoring classified patients as MES-positive or MES-negative.

Results: Data from 31 asymptomatic patients were compared with those from 46 early symptomatic and 35 late phase symptomatic carotid stenosis patients, 23 of whom had undergone carotid intervention. VWF:Ag II levels were higher in early $(12.8 \mu \mathrm{g} / \mathrm{ml}$; $P<0.001)$, late $(10.6 \mu \mathrm{g} / \mathrm{ml} ; \quad P=0.01)$ and late post-intervention $(10.6 \mu \mathrm{g} / \mathrm{ml}$; $P=0.038)$ symptomatic patients than asymptomatic patients $(8.9 \mu \mathrm{g} / \mathrm{ml})$. VWF:Ag levels decreased in symptomatic patients followed up from the early to late phase after symptom onset $(P=0.048)$. Early symptomatic MES-negative patients had higher VWF: Ag II levels (13.3 vs. $9.0 \mu \mathrm{g} / \mathrm{ml} ; P<0.001)$ than asymptomatic MES-negative patients.

Conclusions: Endothelial activation is enhanced in symptomatic versus asymptomatic carotid stenosis patients, in early symptomatic versus asymptomatic MES-negative patients, and decreases over time in symptomatic patients. VWF:Ag II levels are a more sensitive marker of endothelial activation than VWF:Ag levels in carotid stenosis. The potential value of endothelial biomarkers and concurrent cerebral MES detection at predicting stroke risk in carotid stenosis warrants further study.

Correspondence: D. J. H. McCabe, Department of Neurology, Adelaide and Meath Hospital, Dublin, incorporating the National Childrens Hospital, Tallaght, Dublin 24, Ireland (tel.: +353 14144217; fax: +353+1+4143031; e-mail: dominick.mccabe@amnch.ie). 


\section{Introduction}

von Willebrand factor (VWF:Ag) is an adhesive multimeric plasma glycoprotein synthesized in vascular endothelial cells and megakaryocytes [1,2]. von Willebrand factor propeptide (VWF:Ag II) is produced by cleavage of pro-VWF into VWF:Ag and VWF:Ag II $[3,4]$. Endothelial cells secrete VWF into circulating blood or the subendothelial matrix, or may store VWF in endothelial Weibel-Palade bodies [5]. VWF:Ag II undergoes endoproteolytic cleavage to form VWF:Ag in endothelial cells and is also stored in Weibel-Palade bodies until released during endothelial activation [3]. VWF:Ag II is believed to be a more sensitive marker of acute endothelial cell activation than VWF:Ag because VWF:Ag II has a shorter plasma half-life and returns to baseline concentration briskly after the stimulus to endothelial activation is removed [3,4]. The mechanisms responsible for the higher risk of stroke in patients with recently symptomatic than asymptomatic carotid stenosis are not fully understood [6-9] but could relate to differences in platelet activation or endothelial activation status between groups [10-12]. Prior to the conduct of this study, there were limited data on VWF in transient ischaemic attack (TIA) and ischaemic stroke due to carotid stenosis $[13,14]$. Some studies have demonstrated elevated plasma VWF levels in the early $[1,14-17]$ and late $[16,18]$ phases following TIA or ischaemic stroke versus healthy controls. Very few studies have investigated plasma VWF levels specifically in patients with asymptomatic or symptomatic carotid stenosis [19-22].

Previous studies have illustrated the potential role of microembolic signals (MESs) detected on transcranial Doppler ultrasound (TCD) or carotid plaque imaging in identifying asymptomatic and symptomatic carotid stenosis patients who may benefit most from optimal medical or surgical therapy to prevent TIA or stroke [6,23-26]. To our knowledge, simultaneous quantification of plasma levels of VWF:Ag and VWF: Ag II or the VWF:Ag/VWF:Ag II ratio has not been performed in patients with asymptomatic versus symptomatic carotid stenosis, in conjunction with simultaneous quantification of cerebral MESs.

The aims of this pilot study were to determine whether there were differences in endothelial activation ex vivo between patients with asymptomatic and recently symptomatic moderate or severe carotid stenosis, and whether endothelial activation decreased over time in recently symptomatic carotid stenosis patients. A comparison was also made of endothelial activation in asymptomatic and symptomatic subgroups who were MES-positive and MES-negative. It was hypothesized that endothelial activation would be increased in recently symptomatic compared with asymptomatic carotid stenosis, and that endothelial activation would decrease during longitudinal followup in recently symptomatic patients. It was also hypothesized that endothelial activation data would be informative in certain patient subgroups stratified according to MES status [12].

\section{Methods}

Consecutive eligible patients $>18$ years old with asymptomatic or symptomatic moderate or severe carotid artery stenosis or carotid occlusion, identified on colour Doppler ultrasound using standardized velocity criteria [27,28], were recruited from the Rapid Access Stroke Prevention Service, general neurology and vascular surgery clinics, stroke service, and neurology and vascular surgery wards at two secondary and tertiary referral university teaching hospitals between August 2007 and February 2010 [12].

Patients were included in the asymptomatic carotid stenosis group if they were incidentally noted to have moderate $(50 \%-69 \%)$ or severe $(\geq 70 \%)$ carotid stenosis on colour Doppler ultrasound, e.g. during vascular work-up in a patient with a carotid bruit or coronary artery disease [12]. Asymptomatic patients had no history of TIA or stroke, or had not had a TIA or stroke in the ipsilateral carotid or any other cerebrovascular territory within the preceding 3 years. Patients were included in the symptomatic carotid stenosis group if they recently had a TIA or ischaemic stroke in the vascular territory supplied by a moderate or severe carotid stenosis or carotid occlusion within the preceding 4 weeks (early phase), with symptoms attributed to the stenosed carotid artery of interest. Patients with carotid occlusion were only included if no other cause for stroke or TIA was identified.

Exclusion criteria for asymptomatic and symptomatic patients included active infection, inflammation or neoplasia; platelet count $<120$ or $>450 \times 10^{9} / 1$; myocardial infarction, pulmonary embolism, deep vein thrombosis or major surgery within the preceding 3 months; prior primary intracerebral haemorrhage; known bleeding or clotting diathesis; ongoing unstable coronary or peripheral arterial disease; renal impairment (urea $>10 \mathrm{mM}$ ); or non-steroidal anti-inflammatory drug intake other than prescribed aspirin within the preceding 2 weeks [12]. Patients were subsequently excluded from the symptomatic group if a potential cardioembolic source of embolism was detected within 3 months of recruitment, or if they had symptoms, signs or subsequent neuro-imaging evidence of acute cerebral ischaemia outside the vascular territory supplied by the stenosed carotid artery of interest (see below). 
All patients underwent detailed neurovascular assessment by a neurology research registrar/resident (JAK or WOT) or experienced consultant vascular neurologist (DJHM) to confirm that asymptomatic patients met inclusion criteria and to confirm a diagnosis of large artery atherosclerotic TIA or stroke in the symptomatic cohort. TIA and stroke work-up was performed according to European Stroke Organization guidelines [29]. Information regarding vascular risk factors including hypertension, prior TIA or stroke, ischaemic heart disease, atrial fibrillation, valvular heart disease, diabetes mellitus, hyperlipidaemia, peripheral vascular disease, migraine, family history of stroke, medication intake (including anti-thrombotic therapy), smoking status, alcohol intake, and the method of detection of carotid stenosis was collected prospectively. If antiplatelet therapy was altered by their treating physician in the early phase after presentation, patients were invited to undergo repeat blood testing approximately $14 \pm 7$ days later if they had not undergone carotid intervention by that stage. All symptomatic patients who attended for follow-up were clinically reassessed at each follow-up visit.

In our main cross-sectional study, data from asymptomatic patients were compared with those from early and late phase symptomatic carotid stenosis patients. In our nested longitudinal study in the symptomatic cohort, data from early phase symptomatic patients were compared with those who had prospective follow-up data $\geq 3$ months later.

\section{Blood sampling and laboratory tests}

All subjects were rested for at least $20 \mathrm{~min}$, and careful atraumatic venepuncture was performed from a free-flowing vein using a $21 \mathrm{G}$ butterfly needle and a Vacutainer system (Becton Dickinson, Oxford) with a luer adaptor $[16,30,31]$. After taking an ethylenediaminetetraacetic acid sample and seven further $3 \mathrm{ml}$ $3.2 \%$ citrate-anticoagulated whole blood samples, double spun platelet poor plasma (PPP) was obtained from the second to the sixth citrate-anticoagulated tubes by centrifugation and stored at $-80^{\circ} \mathrm{C}$ within $1 \mathrm{~h}$ of venepuncture. Samples were thawed once at $37^{\circ} \mathrm{C}$ for $20 \mathrm{~min}$ before analysis in a VWF:Ag enzyme-linked immunosorbent assay (ELISA). Samples were then refrozen, stored at $-80^{\circ} \mathrm{C}$, and thawed once more for the VWF:Ag II ELISAs. The concentrations of VWF:Ag and VWF:Ag II in each PPP sample were quantified as described previously to assess endothelial activation status [32,33]. In brief, polyclonal rabbit anti-human VWF antibody (DAKO) was used as coating antibody and polyclonal rabbit anti-human VWF/HRP antibody (DAKO) as detection antibody for the VWF:Ag ELISA. M193902 CLB-Pro 35 coating antibody (Plesmanlaan 125) and M103904HRP CLB-Pro 14.3 detection antibody (Plesmanlaan 125) were used for VWF:Ag II quantification. The ELISA result was measured by spectrophotometry at $490 \mathrm{~nm}$, using a VERSA Max Tuneable Microplate Reader. VWF:Ag and VWF:Ag II levels were recorded as micrograms per millilitre.

\section{Transcranial Doppler ultrasound}

Bilateral simultaneous $1 \mathrm{~h} \mathrm{TCD}$ recordings of the middle cerebral artery were performed by one of two highly experienced operators (JAK or WOT) with a Viassys Pioneer TC8080, as described previously [12]. As reported previously, inter-observer agreement regarding the presence or absence of MESs between the first author and an experienced independent observer (MS) blinded to clinical details, symptomatic status and recorded MES status of the study subjects was found to be 'excellent' (93\% concordance; Cohen's unweighted kappa statistic 0.89) [12,34]. Therefore, all remaining TCD data analysis was performed locally by the first author. The study was approved by the research ethics committee at AMNCH/St James's Hospital (Project/REC Reference 2007/03/01). Written informed consent, or assent from a relative where appropriate, was obtained from all participants.

\section{Statistical methods}

Paired or unpaired $t$ tests were used for comparison of paired and unpaired parametric variables, respectively. The Wilcoxon signed rank and the Wilcoxon rank sum tests were used for comparison of paired and unpaired non-parametric variables, respectively, and the Kruskal-Wallis rank sum test for comparison of multiple non-parametric variables, where appropriate. Differences in proportions between groups were assessed with Chi-squared or Fisher exact tests, where appropriate. Multiple linear regression analysis was performed to examine the potential influence of independent demographic or vascular risk factors on any observed differences between groups, where appropriate. Correlation between variables was assessed with the Pearson product moment coefficient $(r)$. Subgroup analyses in symptomatic and asymptomatic patients on aspirin monotherapy and patients with severe $(\geq 70 \%)$ carotid stenosis were also planned. Because simultaneous measurements of VWF:Ag and VWF:Ag II had not previously been performed in asymptomatic versus symptomatic carotid stenosis, power calculations for this study were not possible. The number of subjects chosen for this novel pilot study was based on power 
calculations for a study powered to detect differences in platelet activation status between these patient groups [12]. $P<0.05$ was considered statistically significant. All statistical calculations were performed with $\mathrm{R}$ version 2.15.2 [35].

\section{Results}

Thirty-one patients with asymptomatic carotid stenosis and 61 early phase symptomatic carotid stenosis patients were initially recruited [12]. Fifteen early phase symptomatic patients were subsequently excluded [12], leaving data from 46 patients for analysis, six of whom had symptomatic internal carotid artery occlusion. Of the remaining 40 symptomatic patients in whom intervention could be considered, 28 underwent carotid endarterectomy, one had carotid stenting, six declined surgical intervention and the remaining five chose optimal medical management based on advice from their physician. Thirty-five symptomatic patients attended for late phase follow-up. Two developed $50 \%-69 \%$ carotid restenosis, and one developed $>70 \%$ restenosis on repeat colour Doppler ultrasound at least 3 months after endarterectomy. Two patients had a 'perioperative' ischaemic stroke following carotid endarterectomy: one awoke following endarterectomy with a new ischaemic stroke, and one developed symptoms 48 hours post-operatively. Major surgery within the preceding 3 months was an exclusion criterion for 'laboratory reassessment' during follow-up according to our pre-planned study protocol because platelet activation results could potentially be influenced by the effects of the carotid intervention itself. Therefore, although these events were captured during our data collection period, the 'late phase' clinical and laboratory study reassessment in these cases had to be deferred for at least 3 months after carotid intervention. No patients experienced a recurrent 'non-perioperative' TIA or stroke during follow-up to the late phase at least 3 months after symptom onset or intervention. Eleven symptomatic patients did not have available late phase laboratory data: six declined follow-up, one moved and could not re-attend, one developed active severe symptomatic peripheral vascular disease, and another ongoing active inflammatory gouty arthropathy precluding laboratory reassessment according to our study protocol; two died from unrelated causes (respiratory sepsis and cholecystitis).

There was a higher prevalence of current smokers but a lower prevalence of hypertension amongst symptomatic patients, and a lower prevalence of statin use amongst early symptomatic than asymptomatic patients (Table 1). Otherwise, demographic and vascular risk profiles were similar in asymptomatic and symptomatic patients.
Table 1 Demographic and vascular risk factor profile of patients with endothelial activation data

\begin{tabular}{|c|c|c|c|}
\hline Parameter & $\begin{array}{l}\text { Asymptomatic } \\
\text { carotid stenosis } \\
(n=31)\end{array}$ & $\begin{array}{l}\text { Early } \\
\text { symptomatic } \\
\text { carotid } \\
\text { stenosis } \\
(n=46)\end{array}$ & $\begin{array}{l}\text { Late } \\
\text { symptomatic } \\
\text { carotid } \\
\text { stenosis } \\
(n=35)\end{array}$ \\
\hline Mean age (years) & $68.2( \pm 7.95)$ & $65.0( \pm 9.58)$ & $65.0( \pm 9.9)$ \\
\hline$P$ value & & 0.78 & 0.78 \\
\hline $\operatorname{Sex}(M ; \%)$ & $18(58 \%)$ & $28(61 \%)$ & $20(57 \%)$ \\
\hline$P$ value & & 0.8 & 0.94 \\
\hline $\begin{array}{l}\text { Median interval } \\
\text { from symptom } \\
\text { onset (days; range) }\end{array}$ & $\mathrm{N} / \mathrm{A}$ & $7.5(0-27)$ & $175(99-360)$ \\
\hline \multicolumn{4}{|l|}{ Degree of stenosis } \\
\hline $\begin{array}{l}\text { Moderate: } \\
\geq 50 \%-69 \%\end{array}$ & $11(35 \%)$ & $7(15 \%)$ & $15(43 \%)$ \\
\hline$P$ value & & 0.039 & 0.54 \\
\hline $\begin{array}{l}\text { Severe: } \\
\quad \geq 70 \%-99 \%\end{array}$ & $20(65 \%)$ & $33(72 \%)$ & $9(26 \%)$ \\
\hline$P$ value & & 0.50 & 0.0015 \\
\hline Occlusion & 0 & $6(13 \%)$ & $4(11 \%)$ \\
\hline$P$ value & & 0.04 & 0.07 \\
\hline \multicolumn{4}{|l|}{ Antiplatelet therapy } \\
\hline $\begin{array}{l}\text { Aspirin } \\
\text { monotherapy }\end{array}$ & $22(71 \%)$ & $35(76 \%)$ & $15(43 \%)$ \\
\hline$P$ value & & 0.62 & 0.02 \\
\hline $\begin{array}{l}\text { Aspirin/ } \\
\text { dipyridamole } \\
\text { combination }\end{array}$ & $2(6 \%)$ & $4(9 \%)$ & $11(31 \%)$ \\
\hline$P$ value & & 0.54 & 0.01 \\
\hline $\begin{array}{l}\text { Clopidogrel } \\
\text { monotherapy }\end{array}$ & $5(16 \%)$ & $2(4 \%)$ & $6(17 \%)$ \\
\hline$P$ value & & 0.09 & 0.6 \\
\hline $\begin{array}{l}\text { Aspirin/ } \\
\text { clopidogrel } \\
\text { combination }\end{array}$ & $2(6 \%)$ & $5(11 \%)$ & $3(9 \%)$ \\
\hline$P$ value & & 0.4 & 0.6 \\
\hline $\begin{array}{l}\text { Ischaemic } \\
\text { heart disease }\end{array}$ & $7(23 \%)$ & $10(22 \%)$ & $7(20 \%)$ \\
\hline$P$ value & & 0.93 & 0.8 \\
\hline Hypertension & $27(87 \%)$ & $29(63 \%)$ & $23(66 \%)$ \\
\hline$P$ value & & 0.02 & 0.04 \\
\hline Diabetes mellitus & $7(23 \%)$ & $8(17 \%)$ & $6(17 \%)$ \\
\hline$P$ value & & 0.57 & 0.58 \\
\hline $\begin{array}{l}\text { Prior TIA/stroke } \\
\text { before index event }\end{array}$ & $8(26 \%)$ & $7(15 \%)$ & $6(17 \%)$ \\
\hline$P$ value & & 0.25 & 0.39 \\
\hline $\begin{array}{l}\text { Prior venous } \\
\text { thromboembolism }\end{array}$ & $1(3 \%)$ & 0 & 0 \\
\hline$P$ value & & 0.4 & 0.5 \\
\hline $\begin{array}{l}\text { Peripheral vascular } \\
\text { disease }\end{array}$ & $5(16 \%)$ & $5(11 \%)$ & $6(17 \%)$ \\
\hline$P$ value & & 0.5 & 0.91 \\
\hline $\begin{array}{l}\text { Migraine (with or } \\
\text { without aura) }\end{array}$ & $6(19 \%)$ & $5(11 \%)$ & $5(14 \%)$ \\
\hline$P$ value & & 0.3 & 0.58 \\
\hline $\begin{array}{l}\text { Family } \\
\text { history stroke }\end{array}$ & $9(29 \%)$ & $16(35 \%)$ & $12(34 \%)$ \\
\hline$P$ value & & 0.6 & 0.65 \\
\hline
\end{tabular}


Table 1 (Continued)

\begin{tabular}{|c|c|c|c|}
\hline Parameter & $\begin{array}{l}\text { Asymptomatic } \\
\text { carotid stenosis } \\
(n=31)\end{array}$ & $\begin{array}{l}\text { Early } \\
\text { symptomatic } \\
\text { carotid } \\
\text { stenosis } \\
(n=46)\end{array}$ & $\begin{array}{l}\text { Late } \\
\text { symptomatic } \\
\text { carotid } \\
\text { stenosis } \\
(n=35)\end{array}$ \\
\hline Current smokers & $5(16 \%)$ & $21(46 \%)$ & $14(40 \%)$ \\
\hline$P$ value & & 0.007 & 0.03 \\
\hline Ex-smoker & $22(71 \%)$ & $17(37 \%)$ & $13(37 \%)$ \\
\hline$P$ value & & 0.003 & 0.006 \\
\hline Never smoker & $4(13 \%)$ & $8(17 \%)$ & $8(23 \%)$ \\
\hline$P$ value & & 0.59 & 0.3 \\
\hline Statin therapy & $28(90 \%)$ & $33(72 \%)$ & $27(77 \%)$ \\
\hline$P$ value & & 0.043 & 0.13 \\
\hline
\end{tabular}

TIA, transient ischaemic attack. $P$ values relate to chi-squared or Fisher exact testing between asymptomatic and symptomatic carotid stenosis groups. Values are means ( \pm standard deviation) or absolute values. Significant $P$ values are highlighted in bold.

There were no significant differences in unadjusted VWF:Ag levels or in the VWF:Ag/VWF:AgII ratio between the overall population of asymptomatic patients and symptomatic patients at any stage after symptom onset or intervention $(P \geq 0.056)$. However, VWF:Ag II levels were higher in early $(12.8 \mu \mathrm{g} / \mathrm{ml}$; $P<0.001)$, late $(10.6 \mu \mathrm{g} / \mathrm{ml} ; P=0.01)$ and late postintervention $\quad(10.6 \mu \mathrm{g} / \mathrm{ml} ; \quad P=0.038) \quad$ symptomatic patients than asymptomatic carotid stenosis patients $(8.9 \mu \mathrm{g} / \mathrm{ml})$ (Table 2). Within the symptomatic patient group with longitudinal follow-up data, VWF:Ag levels significantly decreased over time from the early to late phase after symptom onset (16.5 vs. $14.8 \mu \mathrm{g} / \mathrm{ml}$, $P=0.048$; Table 3). Otherwise, there were no differences in endothelial activation markers between early symptomatic and late phase symptomatic patients, regardless of whether they underwent intervention (Tables 3 and 4). Having controlled for the independent influence of smoking status, hypertension and statin use with multiple linear regression, adjusted VWF:Ag II levels remained significantly higher in early symptomatic $(P=0.0007)$ and late symptomatic $(P=0.035)$ than asymptomatic patients. Furthermore, differences in adjusted VWF:Ag levels between early symptomatic and asymptomatic patients became significant $(P=0.029)$.

\section{Pre-planned subgroup analyses}

Because differences in prescribed antiplatelet regimens could potentially have influenced observed differences between asymptomatic and symptomatic patients (Table 1), pre-planned subgroup analysis was performed in patients on aspirin monotherapy. VWF:Ag levels (15.4 vs. $12.1 \mu \mathrm{g} / \mathrm{ml} ; P=0.045)$ and VWF:Ag II levels $(12.8$ vs. $8.7 \mu \mathrm{g} / \mathrm{ml} ; P=0.003)$ were higher in early symptomatic than asymptomatic patients on aspirin (Table 5). Otherwise, there were no other differences between symptomatic and asymptomatic carotid stenosis subjects on aspirin monotherapy, but it must be emphasized that smaller numbers of subjects were included in this subgroup analysis. VWF: $\mathrm{Ag}$ II levels were also elevated in early $(12.6 \mu \mathrm{g} / \mathrm{ml}$; $P=0.004)$ and late $(10.9 \mu \mathrm{g} / \mathrm{ml} ; P=0.023)$ symptomatic severe carotid stenosis $(\geq 70 \%)$ versus asymptomatic severe carotid stenosis $(8.8 \mu \mathrm{g} / \mathrm{ml})$ (Table 6). There were no other differences between symptomatic and asymptomatic severe carotid stenosis patients.

\section{Endothelial activation status in MES-positive and MES-negative subgroups}

Twenty-five asymptomatic, 31 early symptomatic and 27 late symptomatic patients had TCD data available for analysis (Table S1) [12]; 12\% asymptomatic vs. $32 \%$ early symptomatic $(P=0.02)$ and $19 \%$ late symptomatic $(P=0.2)$ patients were MES-positive (Table S1) [12].

There were no significant differences in endothelial activation markers between early or late symptomatic versus asymptomatic MES-positive subjects. However, VWF:AgII levels were higher (13.3 vs. $9.0 \mu \mathrm{g} / \mathrm{ml}$; $P<0.001)$ and the VWF:Ag/VWF:Ag II ratio was lower ( 0.95 vs. $1.6 ; P=0.006)$ in early symptomatic

Table 2 Comparison of von Willebrand factor (VWF:Ag), von Willebrand factor propeptide (VWF:Ag II) and the VWF:Ag/VWF:Ag II ratio in asymptomatic versus early symptomatic, late phase symptomatic and post-intervention late symptomatic patients

\begin{tabular}{llccc}
\hline & Asymptomatic & Early symptomatic \\
$(n=31)$ & $156)$ & $\begin{array}{l}\text { Late symptomatic } \\
(n=35)\end{array}$ & $\begin{array}{l}\text { Late symptomatic } \\
\text { post-intervention } \\
(n=23)\end{array}$ \\
Marker & $13.3(9.2-16.1)$ & $15.4(11.9-21.0)$ & $12.8(9.9-19.9)$ & $12.4(9.9-17.7)$ \\
VWF:Ag $(\mu \mathrm{g} / \mathrm{ml})$ & & 0.056 & 0.6 & 0.97 \\
$P$ value & $8.9(3.4-10.4)$ & $12.8(8.6-17.0)$ & $10.6(7.2-17.0)$ & $10.6(7.1-17.0)$ \\
VWF:Ag II $(\mu \mathrm{g} / \mathrm{ml})$ & & $<\mathbf{0 . 0 0 1}$ & $\mathbf{0 . 0 1}$ & $\mathbf{0 . 0 3 8}$ \\
$P$ value & $1.6(1.2-3.3)$ & $1.3(0.8-2.3)$ & $1.3(1.1-1.9)$ & $1.2(0.9-2.1)$ \\
VWF:Ag/VWF:Ag II ratio & & 0.096 & 0.5 & 0.07 \\
$P$ value & & & & 0.5 \\
\hline
\end{tabular}

Values are medians (25th-75th percentile). Significant $P$ values are highlighted in bold. 
Table 3 Endothelial activation data in early versus late symptomatic carotid stenosis patients who had data at each time point

\begin{tabular}{llll}
\hline & $\begin{array}{l}\text { Early } \\
\text { symptomatic } \\
(n=35)\end{array}$ & $\begin{array}{l}\text { Late } \\
\text { symptomatic } \\
(n=35)\end{array}$ & $P$ value \\
\hline VWF:Ag $(\mu \mathrm{g} / \mathrm{ml})$ & $16.5( \pm 6.4)$ & $14.8( \pm 6.4)$ & $\mathbf{0 . 0 4 8}$ \\
VWF:Ag II $(\mu \mathrm{g} / \mathrm{ml})$ & $13.0( \pm 6.0)$ & $11.7( \pm 6.0)$ & 0.33 \\
VWF:Ag/VWF:Ag II ratio & $1.2(0.8-1.8)$ & $1.3(1.1-1.9)$ & 1.0 \\
\hline
\end{tabular}

Values are either means $( \pm \mathrm{SD})$ or medians $(25$ th -75 th percentile). Significant $P$ values are highlighted in bold.

Table 4 Endothelial activation markers in early symptomatic preintervention versus late symptomatic post-intervention carotid stenosis patients

\begin{tabular}{llll}
\hline & $\begin{array}{l}\text { Early } \\
\text { symptomatic } \\
(n=23)\end{array}$ & $\begin{array}{l}\text { Late } \\
\text { symptomatic } \\
(n=23)\end{array}$ & $P$ value \\
\hline VWF:Ag $(\mu \mathrm{g} / \mathrm{ml})$ & $16.0( \pm 6.7)$ & $13.7( \pm 5.7)$ & 0.054 \\
VWF:Ag II $(\mu \mathrm{g} / \mathrm{ml})$ & $11.9( \pm 5.5)$ & $11.2( \pm 5.8)$ & 0.67 \\
VWF:Ag/VWF:Ag II ratio & $1.4(0.9-2.1)$ & $1.2(0.9-2.1)$ & 0.28 \\
\hline
\end{tabular}

Values are means $( \pm \mathrm{SD})$ or medians $(25$ th -75 th percentile).

than asymptomatic MES-negative patients (Table S2). VWF:Ag II levels were also higher in late symptomatic than asymptomatic MES-negative patients (10.7 vs. $9.0 \mu \mathrm{g} / \mathrm{ml} ; P=0.01$; Table S2). Having controlled for differences in smoking prevalence, statin use and hypertension between early symptomatic, late phase symptomatic and asymptomatic MES-negative patients, all above differences in VWF:Ag II levels and the VWF:Ag/VWF:Ag II ratio persisted between relevant subgroups $(P<0.05)$.

\section{Discussion}

This novel longitudinal study has shown convincing evidence of excessive endothelial activation, as evidenced by elevated VWF:Ag II levels in early, late and late post-intervention symptomatic patients and elevated adjusted VWF:Ag levels in early symptomatic versus asymptomatic carotid stenosis patients. Because VWF:Ag II is a marker of acute rather than chronic endothelial cell activation $[3,4]$ the persistent changes during follow-up indicate that the findings in early symptomatic patients are not simply reflective of an acute phase response to recent ocular or cerebral ischaemia or infarction. Furthermore, our data confirm that VWF:Ag II is a more sensitive marker of acute endothelial activation than VWF:Ag in studies comparing patients with symptomatic and asymptomatic carotid stenosis.

VWF:Ag and VWF:Ag II levels were higher in early symptomatic than asymptomatic patients on aspirin monotherapy. These findings indicate that endothelial activation is increased in early symptomatic versus asymptomatic patients despite treatment with low to medium dose aspirin therapy, and that differences in endothelial activation status are not simply explained by differences in antiplatelet regimens between groups. However, because of the relatively small numbers of subjects included in our subgroup analyses, the effects of different antiplatelet regimens on endothelial activation in carotid stenosis deserves further formal study. VWF:Ag II levels were also elevated in early and late symptomatic versus asymptomatic severe carotid stenosis indicating ongoing excessive endothelial activation levels in this higher risk symptomatic subgroup.

Our longitudinal study in symptomatic patients revealed that endothelial activation status (VWF:Ag) decreased as patients were followed up from the early to the late stage after symptom onset or carotid intervention. These findings may partly reflect resolution of the acute phase response over time, the effects of successful removal of the stenosing atherosclerotic plaque in $66 \%$ of patients, and perhaps alteration of antiplatelet therapy in some symptomatic patients by the late stage of follow-up.

Prior to this study, published data supported the concept that MESs predict subsequent TIA or ischaemic stroke risk in patients with $>60 \%[6,23-25]$ and $\geq 70 \%$ asymptomatic carotid artery stenosis [26,36].

Table 5 Comparison of VWF:Ag, VWF:Ag II and the VWF:Ag/VWF:Ag II ratio in asymptomatic versus early symptomatic, late phase symptomatic and post-intervention late phase symptomatic patients on aspirin monotherapy

\begin{tabular}{|c|c|c|c|c|}
\hline Marker & $\begin{array}{l}\text { Asymptomatic } \\
(n=22)\end{array}$ & $\begin{array}{l}\text { Early symptomatic } \\
(n=30)\end{array}$ & $\begin{array}{l}\text { Late symptomatic } \\
(n=15)\end{array}$ & $\begin{array}{l}\text { Late symptomatic } \\
\text { post-intervention } \\
(n=10)\end{array}$ \\
\hline VWF:Ag $(\mu \mathrm{g} / \mathrm{ml})$ & $12.1(9.1-16.5)$ & $15.4(12.2-20.2)$ & $10.9(8.9-17.2)$ & $10.7(7.9-14.7)$ \\
\hline$P$ value & & 0.045 & 0.8 & 0.52 \\
\hline VWF:Ag II $(\mu \mathrm{g} / \mathrm{mL})$ & $8.7(3.5-10.5)$ & $12.8(8.6-17.6)$ & $9.4(6.6-15.7)$ & $10.6(6.6-18.2)$ \\
\hline$P$ value & & 0.003 & 0.38 & 0.35 \\
\hline VWF:Ag/VWF:Ag II ratio & $2.0(1.1-3.5)$ & $1.2(0.8-1.8)$ & $1.4(1.1-1.8)$ & $1.1(0.8-1.9)$ \\
\hline$P$ value & & 0.07 & 0.28 & 0.21 \\
\hline
\end{tabular}

Values are means $( \pm \mathrm{SD})$ or medians (25th-75th percentile). Significant $P$ values are highlighted in bold. 
Table 6 Comparison of endothelial activation in asymptomatic versus early symptomatic and late phase symptomatic subjects with severe $(\geq 70 \%)$ carotid stenosis

\begin{tabular}{llll}
\hline Asymptomatic & $\begin{array}{l}\text { Early } \\
\text { symptomatic } \\
(n=33)\end{array}$ & $\begin{array}{l}\text { Late } \\
\text { symptomatic } \\
(n=9)\end{array}$ \\
\hline $\begin{array}{c}\text { VWF:Ag } \\
(\mu \mathrm{g} / \mathrm{mL})\end{array}$ & $13.8(9.4-16.9)$ & $15.1(10.2-19.3)$ & $12.6(10.5-15.9)$ \\
$\begin{array}{c}P \text { value } \\
\text { VWF:Ag II } \\
(\mu \mathrm{g} / \mathrm{mL})\end{array}$ & $8.8(3.2-10.0)$ & $12.6(7.8-16.9)$ & $10.9(7.7-18.2)$ \\
$\begin{array}{l}P \text { value } \\
\text { VWF:Ag/ } \\
\text { VWF:Ag II } \\
\text { ratio }\end{array}$ & $1.8(1.4-3.9)$ & $1.2(0.8-1.9)$ & $1.3(1.1-1.8)$ \\
$P$ value & & 0.023 & \\
\hline
\end{tabular}

Values are medians (25th-75th percentile).

However, to our knowledge, no studies compared both endothelial activation status and MESs in asymptomatic versus early and late symptomatic $\geq 50 \%$ carotid stenosis or symptomatic patients followed up to the late phase after symptom onset or intervention. The finding of higher VWF:Ag II levels in early and late phase symptomatic than in asymptomatic MES-negative patients suggests persistent excessive endothelial activation in this important subgroup of symptomatic patients who do not have detectable emboli on TCD, despite treatment with antithrombotic and other secondary preventive therapy. However, one must accept that the number of subjects included in the different subgroups in this analysis that was stratified according to MES status was limited; therefore, these data must be interpreted with caution and need to be confirmed in further studies with much larger numbers of subjects.

Spence et al. previously reported that plasma total homocysteine levels were higher in asymptomatic carotid stenosis patients who were MES-positive [6,23]. Although these levels would have been very interesting to assess in our study, dedicated funding was not available to measure plasma total homocysteine levels in all of our patients. However, simultaneous quantification of homocysteine, VWF:Ag and VWF:Ag II levels and MESs definitely warrants further study.

We cannot make any definitive conclusions at present about the value of these biomarkers in predicting the risk of recurrent vascular events in patients with carotid stenosis because none of our patients had 'non-perioperative' recurrent vascular events during medium-term follow up in this study. These data enhance our understanding of the importance of endothelial activation in carotid stenosis and of the cellular mechanisms potentially responsible for the disparity in stroke risk between symptomatic and asymptomatic carotid stenosis patients. Therapeutic agents that specifically inhibit the VWF pathway have the potential to subsequently reduce endothelial activation and platelet activation or reactivity, and hence the risk of recurrent vascular events in this important patient population with moderate to severe carotid stenosis [37].

\section{Acknowledgements}

Dr Kinsella's research was funded by the Stanley Thomas Johnson Foundation and by unrestricted educational grant funding from Bayer Schering Ireland, Pfizer Ireland and Elitech UK. Dr Tobin's research was funded by the IICN-Serono Fellowship, Meath Foundation, Lundbeck Neurosciences Bursary programme and by unrestricted educational grant funding from Merck Serono Ireland, Brennan and Company, Ireland, and Biogen Idec Ireland Limited. Dr McCabe's research programme was part funded by grant support from the Programme for Research in Third Level Institutions in Ireland (Cycle 4), cofunded by the European Regional Development Fund.

\section{Disclosure of conflicts of interest}

The authors declare no financial or other conflicts of interest.

\section{Supporting Information}

Additional Supporting Information may be found in the online version of this article:

Table S1. Demographic data and risk factor profiles of study patients with available TCD data.

Table S2. Comparison of endothelial activation in asymptomatic versus early symptomatic and late phase symptomatic carotid stenosis patients who were MES-negative. 


\section{References}

1. Bongers TN, de Maat MP, van Goor ML, et al. High von Willebrand factor levels increase the risk of first ischaemic stroke: influence of ADAMTS13, inflammation, and genetic variability. Stroke 2006; 37: 2672-2677.

2. Nishio K, Anderson PJ, Zheng XL, et al. Binding of platelet glycoprotein $\mathrm{Ib}$ alpha to von Willebrand factor domain A1 stimulates the cleavage of the adjacent domain A2 by ADAMTS13. Proc Natl Acad Sci U S A 2004; 101: 10578-10583.

3. van Mourik JA, Boertjes R, Huisveld IA, et al. von Willebrand factor propeptide in vascular disorders: a tool to distinguish between acute and chronic endothelial cell perturbation. Blood 1999; 94: 179-185.

4. Frijns CJ, Kasius KM, Algra A, et al. Endothelial cell activation markers and delayed cerebral ischemia in patients with subarachnoid haemorrhage. J Neurol Neurosurg Psychiatry 2006; 77: 863-867.

5. Ruggeri ZM, von Willebrand factor. J Clin Invest 1997; 100: $\mathrm{S} 41-\mathrm{S} 46$.

6. Spence JD, Coates V, Li H, et al. Effects of intensive medical therapy on microemboli and cardiovascular risk in asymptomatic carotid stenosis. Arch Neurol 2010; 67: $180-186$.

7. Marquardt L, Geraghty OC, Mehta Z, et al. Low risk of ipsilateral stroke in patients with asymptomatic carotid stenosis on best medical treatment: a prospective, population-based study. Stroke 2010; 41: e11-e17.

8. Abbott AL. Medical (nonsurgical) intervention alone is now best for prevention of stroke associated with asymptomatic severe carotid stenosis: results of a systematic review and analysis. Stroke 2009; 40: e573-e583.

9. Naylor AR. Time to rethink management strategies in asymptomatic carotid artery disease. Nat Rev Cardiol 2012; 9: 116-124.

10. McCabe DJ, Harrison P, Mackie IJ, et al. Increased platelet count and leucocyte-platelet complex formation in acute symptomatic compared with asymptomatic severe carotid stenosis. J Neurol Neurosurg Psychiatry 2005; 76: 1249-1254.

11. Cha JK, Jeong MH, Jang JY, et al. Serial measurement of surface expressions of CD63, P-selectin and CD40 ligand on platelets in atherosclerotic ischaemic stroke. A possible role of CD40 ligand on platelets in atherosclerotic ischaemic stroke. Cerebrovasc Dis 2003; 16: 376 382.

12. Kinsella $\mathbf{J}$, Tobin $\mathrm{W}$, Tierney $\mathrm{S}$, et al. Increased platelet activation in early symptomatic versus asymptomatic carotid stenosis and relationship with microembolic status: results from the Platelets and Carotid Stenosis (PACS) Study. J Thromb Haemost 2013; 11: 1407-1416.

13. Catto AJ, Carter AM, Barrett JH, et al. von Willebrand factor and factor VIII:C in acute cerebrovascular disease. Relationship to stroke subtype and mortality. Thromb Haemost 1997; 77: 1104-1108.

14. Sonneveld MA, van Dijk AC, van den Herik EG, et al. Relationship of von Willebrand factor with carotid artery and aortic arch calcification in ischaemic stroke patients. Atherosclerosis 2013; 230: 210-215.

15. Lynch JR, Blessing R, White WD, et al. Novel diagnostic test for acute stroke. Stroke 2004; 35: 57-63.
16. McCabe DJ, Harrison P, Mackie IJ, et al. Assessment of the antiplatelet effects of low to medium dose aspirin in the early and late phases after ischaemic stroke and TIA. Platelets 2005; 16: 269-280.

17. Kozuka K, Kohriyama T, Nomura E, et al. Endothelial markers and adhesion molecules in acute ischaemic stroke - sequential change and differences in stroke subtype. Atherosclerosis 2002; 161: 161-168.

18. Kain K, Catto AJ, Young J, et al. Increased fibrinogen, von Willebrand factor and tissue plasminogen activator levels in insulin resistant South Asian patients with ischaemic stroke. Atherosclerosis 2002; 163: 371-376.

19. With Noto AT, Bogeberg ME, Amiral J, et al. Endothelial dysfunction and systemic inflammation in persons with echolucent carotid plaques. Thromb Haemost 2006; 96: $53-59$.

20. Nilsson TK, Spence JD, Nilsson PM, et al. Quantitative measurement of carotid atherosclerosis in relation to levels of von Willebrand factor and fibrinolytic variables in plasma - a 2-year follow-up study. J Cardiovasc Risk 2002; 9: 215-221.

21. Blann AD, Farrell A, Picton A, et al. Relationship between endothelial cell markers and arterial stenosis in peripheral and carotid artery disease. Thromb Res 2000; 97: 209-216.

22. Xia ZY, Yang H, Qu HQ, et al. Expression of P-selectin, von Willebrand and endothelin-1 after carotid artery stenting. Vasa 2011; 40: 199-204.

23. Spence JD, Tamayo A, Lownie SP, et al. Absence of microemboli on transcranial Doppler identifies low-risk patients with asymptomatic carotid stenosis. Stroke 2005; 36: 2373-2378.

24. Madani A, Beletsky V, Tamayo A, et al. High-risk asymptomatic carotid stenosis: ulceration on 3D ultrasound vs TCD microemboli. Neurology 2011; 77: 744-750.

25. Molloy J, Markus HS. Asymptomatic embolization predicts stroke and TIA risk in patients with carotid artery stenosis. Stroke 1999; 30: 1440-1443.

26. Markus HS, King A, Shipley M, et al. Asymptomatic embolisation for prediction of stroke in the Asymptomatic Carotid Emboli Study (ACES): a prospective observational study. Lancet Neurol 2010; 9: 663-671.

27. Sidhu PS, Allan PL. Ultrasound assessment of internal carotid artery stenosis. Clin Radiol 1997; 52: 654-658.

28. Grant EG, Benson CB, Moneta GL, et al. Carotid artery stenosis: gray-scale and Doppler US diagnosis Society of Radiologists in Ultrasound Consensus Conference. Radiology 2003; 229: 340-346.

29. European Stroke Organisation (ESO) Executive Committee; ESO Writing Committee. Guidelines for management of ischaemic stroke and transient ischaemic attack 2008. Cerebrovasc Dis 2008; 25: 457-507.

30. Kinsella JA, Tobin WO, Cox D, et al. Prevalence of ex vivo high on-treatment platelet reactivity on antiplatelet therapy after transient ischaemic attack or ischaemic stroke on the PFA-100 and VerifyNow. J Stroke Cerebrovasc Dis 2012; 12: S1052-S3057.

31. Tobin WO, Kinsella JA, Collins DR, et al. Enhanced ex vivo inhibition of platelet function following addition of dipyridamole to aspirin after transient ischaemic attack or ischaemic stroke: first results from the TRinity AntiPlatelet responsiveness (TrAP) study. $\mathrm{Br} J$ Haematol 2011; 152: 640-647. 
32. O'Donnell JS, McKinnon TA, Crawley JT, et al. Bombay phenotype is associated with reduced plasma-VWF levels and an increased susceptibility to ADAMTS13 proteolysis. Blood 2005; 106: 1988-1991.

33. Preston RJ, Morse C, Murden SL, et al. The protein C omega-loop substitution Asn2Ile is associated with reduced protein $\mathrm{C}$ anticoagulant activity. $\mathrm{Br} \mathrm{J}$ Haematol 2009; 144: 946-953.

34. Cohen J. Weighted kappa: nominal scale agreement with provision for scaled disagreement or partial credit. Psychol Bull 1968; 70: 213-220.
35. R Development Core Team. R: A Language and Environment for Statistical Computing. [2.15.2]. 2012. Vienna, Austria. R Foundation for Statistical Computing. http:// www.r-project.org/.

36. Topakian R, King A, Kwon SU, et al. ACES Investigators. Ultrasonic plaque echolucency and emboli signals predict stroke in asymptomatic carotid stenosis. Neurology 2011; 77: 751-758.

37. De Meyer SF, Stoll G, Wagner DD, et al. von Willebrand factor: an emerging target in stroke therapy. Stroke 2012; 43: 599-606. 